\title{
COMUNIDADE DA MODERNIDADE LÍQUIDA E COCRIAÇÃO DE VALOR NA RESPONSABILIDADE SOCIAL CORPORATIVA
}

\author{
Paulo Roberto Oliveira \\ Doutorando em Administração \\ Universidade do Vale do Itajá Itajaí - SC - Brasil \\ pvieiradeoliveira@gmail.com https://orcid.org/0000-0002-4809-6721 \\ Hellen Taynan Cavalcanti \\ Doutoranda em Administração \\ Universidade Federal de Minas Gerais Belo Horizonte - MG - Brasil \\ hellentaynan@gmail.com http://orcid.org/0000-0003-2672-6726 \\ Anete Alberton \\ Doutora em Engenharia de Produção \\ Universidade do Vale do Itajaí Itajaí - SC - Brasil \\ anete@univali.br http://orcid.org/0000-0002-6477-0122
}

\section{RESUMO}

Este ensaio teórico tem o objetivo de desenvolver um primeiro esforço de pesquisa no sentido de apontar e demonstrar a semelhança entre os elementos da comunidade de Bauman e os diálogos virtuais de Responsabilidade Social Corporativa. Exploramos o conceito de comunidade identificando conexões com o sentido de cocriação de valor na RSC no modelo de Korschun e Du. Propomos um diálogo entre tais áreas, focando especificamente nas comunidades virtuais. Pelos conceitos expostos, discutimos que a comunidade se torna um lugar comum ao diálogo para cocriação de valor. Tal discussão promove questionamentos, reflexões e identifica um campo possível para estudos futuros. Por tratar de temas emergentes na academia, esse trabalho se destaca pela originalidade capaz de contribuir para o avanço nos estudos na administração, unindo aspectos da RSC ao sentido de comunidade, numa perspectiva sociológica. Suportamos teoricamente uma possível conexão entre a comunidade de Bauman e o sentido de comunidade nos diálogos virtuais nas comunidades de RSC, de modo que os dois elementos agem como se houvesse a presença de laços entre eles. Esse respaldo se dá pela visão de Bauman a respeito do sentido de comunidade impulsionado pela comunicação. Nesse contexto, os estudos de Granovetter nos auxiliam ao indicar que os laços em redes sociais são elementos capazes de contribuir para a coesão social.

Palavras-chave: Cocriação de valor. Comunicação. Comunidade. Responsabilidade social corporativa.

\section{NET MODERNITY COMMUNITY AND CO-CREATION OF VALUE IN CORPORATE SOCIAL RESPONSIBILITY}

\section{ABSTRACT}

This theoretical essay aims to develop a first research effort in order to point out and demonstrate the similarity between the elements of the Bauman community and the virtual dialogues of Corporate Social Responsibility. We explore the concept of community by identifying connections with the sense of cocreating value in CSR in the Korschun and Du model. We propose a dialogue between these areas, focusing on virtual communities. Due to the exposed concepts, the debates about the community become a common place for the value co-creation dialogue. Such discussion promotes questions, reflections and identifies a possible field for future studies. As it addresses emerging themes in academia, the work is registered for its originality capable of contributing to the advancement of management studies, uniting aspects of CSR to the sense of the community, in a sociological perspective. Theoretically, it supports a possible connection between the Bauman community and the meaning of the community in the virtual dialogues in the RSC communities, so that the two elements are also as if there were links between them. This support is given by Bauman's view of the meaning of the community driven by communication. In this context, Granovetter's studies help us to indicate that ties in social networks are elements capable of contributing to social cohesion.

Key words: Communication. Community. Corporate social responsibility. Value co-creation.

Data da submissão: $27 / 10 / 2019$

Data de aceite: $23 / 05 / 2020$ 
Comunidade da modernidade líquida e cocriação de valor na responsabilidade social corporativa

\section{INTRODUÇÃO}

Tomando como base o conceito de modernidade líquida criado pelo sociólogo polonês Zygmunt Bauman, caracterizamos a sociedade pelo desapego aos padrões existentes, o rompimento das estruturas sólidas, da estrutura fabril, dos empregos vitalícios e dos relacionamentos duradouros (Bauman, 2001). O autor faz críticas ao capitalismo ao explicar que, nessa fase da modernidade, o consumo se mostra capaz de passar com uma velocidade avassaladora sobre as necessidades dos indivíduos (Bauman, 2003; 2008). Bauman (2001) aborda a existência de cinco dimensões no que ele chama modernidade líquida: emancipação, individualidade, tempo/espaço, trabalho e comunidade, e as utiliza para descrever como ocorreu a passagem da modernidade sólida para a que estamos nos dias atuais.

A modernidade líquida é marcada pela impermanência na qual a mudança contínua de formas parece ser interminável (Saraiva \& Veiga-Neto, 2009). Por um lado, tem-se a necessidade que as pessoas e organizações em geral exibam seus feitos, a fim de conseguir aprovação e prestígio num sentido de pertencimento por meio do consumo (Lazzarato, 2006). Por outro lado, em nossa sociedade contemporânea, reside o fato de que as empresas que não cumprem sua parte no movimento em busca da melhoria da qualidade de vida da sociedade e de seus indivíduos, podem acabar sofrendo sanções ou repúdio por parte de seus consumidores, já que atender demandas de interesse comunitário está ligado ao retorno em termos mercadológicos (Sen et al., 2001; Ethos, 2002; Cruz, 2013; Sales et al., 2019). Cresce, portanto, a pressão sobre as corporações para exercerem sua responsabilidade social corporativa - RSC da forma mais positiva possível, respondendo às expectativas econômicas, legais, éticas e discricionárias que a sociedade possui (Yin et al., 2015).

Dessa forma, uma comunicação adequada pode construir uma reputação corporativa forte junto aos seus stakeholders (Morsing \& Schultz, 2006; Du et al., 2010; Scharf; Fernandes, 2013; Su et al., 2017). Essa construção poderá conduzir a relacionamentos mais duradouros da empresa com as diversas partes interessadas (Bortree, 2014). Isso se torna relevante ao considerar que os consumidores apoiam organizações socialmente responsáveis por meio de sua comunicação de responsabilidade social corporativa (Kim, 2017; Su et al., 2017; Uzunoğlu et al., 2017). O que corrobora a ideia de que na modernidade líquida o ideal de atender às necessidades comunitárias contribui para ganhos monetários se dá à medida que atrai mais consumidores interessados em manter sua imagem vinculada a empresas que desenvolvam boas práticas junto à sociedade.

Essa comunicação pode ocorrer em diferentes formatos: na mídia impressa, nos canais web das organizações, por meio de anúncios publicitários e nas mídias sociais digitais. E é graças à crescente onda de utilização das mídias sociais que o tema da responsabilidade social corporativa é cada vez mais abordado por empresas e usuários nesses meios. Yin et al. (2015) reforçam o pensamento de Morsing e Schultz (2006) sinalizando que os gestores precisam escutar a sociedade e participar das conversas nas mídias sociais.

Além desses fatores, dentro das mídias sociais, incluindo as redes sociovirtuais, há debates sobre assuntos específicos em organizações de indivíduos também específicas, conhecidas como comunidades virtuais. Nestas comunidades, destacam-se os intensos diálogos que podem levar a um melhor conhecimento sobre diversos temas, incluindo aqueles sobre as ações de responsabilidade social corporativa que as empresas estão desenvolvendo. Korschun e Du (2013) apresentam um framework que explica como os stakeholders interpretam e respondem aos diálogos virtuais de responsabilidade social corporativa. Eles evidenciam que os diálogos geram valor com base na identificação das partes interessadas com a comunidade de participantes do diálogo e com base nas expectativas aumentadas que os stakeholders desenvolvem. Esse movimento é denominado pelos autores como cocriação e, seguindo a compreensão ora adotada, torna-se relevante.

Tal como identificado por Hildebrand et al. (2011), a responsabilidade social corporativa parece ser um veículo quase perfeito para os esforços de marketing corporativo da maioria das empresas, porém, necessita ser realizada de maneira que os stakeholders se identifiquem com a 
empresa, de forma que as ações não sejam impostas e sim cocriadas. Neste sentido, ações cocriadas, se tornam legitimadas pelas partes interessadas. No entanto, para isso, aqueles que estão participando desta cocriação de valor, precisam estar motivados a tomarem essa ação. Quanto a isto, uma possibilidade de abordagem teórica é concebida à luz da teoria da legitimidade originalmente proposta por Gray, Kouhy e Lavers (1995). Nesta proposta, os autores estabelecem que a organização faz parte de um sistema social e precisam ter suas ações legitimadas pelos diversos stakeholders que, por sua vez, são impactados por ela.

Aliado a isso, há o entendimento que as organizações não conseguem mais, somente pelos meios tradicionais, comunicar suas ações de RSC. É preciso que essas ações sejam legitimadas pela sociedade de forma mais eficaz. Isso se torna pertinente, pois os indivíduos estão cada vez mais presentes nas redes sociais, tornando a vida virtual uma extensão de sua vida real (Polivanov, 2013; Kozinets, 2014).

A nova dinâmica macrossocial, que inclui as comunidades em ambientes virtuais, deve ser pensada em termos da necessidade de mudança nas representações sociais e da forma como cada um dos problemas é pensado. Nesse sentido, as dimensões não materiais da vida social nos processos de mudança social são relevantes de serem pesquisadas (Casas, 2005). No estudo de Pedersen e Thing (2016) sobre corredores de rua, por exemplo, os autores encontram a existência de um sentido mais profundo de comunidade. Entretanto, pode-se dizer que o mesmo sentido existe em comunidades de responsabilidade social corporativa? O trabalho de Casas (2005) destaca a importância de estudos que verifiquem a influência dos meios de comunicação nos processos de mudança social. Desse modo, ao tomarmos a publicação de Casas (2005) e, onze anos após, o estudo de Pedersen e Thing (2016), percebemos a pertinência de discussão deste ensaio, não só pelo lapso temporal quanto pela consideração das mudanças no processo macrossocial que pode ser afetado pela comunicação, no sentido de criar valor para a empresa, ou mesmo fazer perdê-la este valor a depender de suas ações.

Com respeito ao tema da responsabilidade social corporativa, tem-se que este é amplamente pesquisado academicamente, contudo o debate não se esgota considerando os desafios das empresas no século XXI. Uma evidência está nas buscas pelo termo em periódicos Capes dos últimos cinco anos que resultam 259 publicações em 20 periódicos revisados por pares no Brasil.

Por outro lado, associando o termo da RSC aos debates de Bauman apenas três publicações retornam da busca e quando relacionamos à modernidade líquida, não temos nenhum resultado. Tal fato indica que, apesar da pertinência para o debate, as discussões são poucas no contexto pretendido. Pesquisa na base da Scopus com as palavras co-creation AND csr AND community, resultou em oito artigos, ao passo que a busca por community and csr no abstract e, depois, incluindo communication, reputation e stakeholder, retornam grande quantidade de artigos. De outro modo, apesar de as discussões sobre comunidade à luz de Bauman terem recebido notoriedade, resultando 216 publicações de 2015 a 2020, pontua-se que não encontramos, dentre as publicações, uma análise aprofundada em relação a dinâmica macrossocial no sentido das comunidades em contexto sociovirtual.

O sentido de comunidade é explorado no estudo de Pedersen et al. (2018), quando os autores identificam os corredores sérios como àqueles que treinam em equipes, que são uniformizados e que possuem um propósito compartilhado (a realização de treinamentos e corridas). Nas comunidades de corredores, das quais eles participam, as diferenças pessoais são eliminadas - os corredores não conhecem as vidas pessoais uns dos outros, seus trabalhos e nada que conduza à sua individualidade, havendo a caracterização do grupo pela homogeneidade e igualdade. Relacionando aos conceitos de Granovetter (1973), os corredores sérios estabeleceriam uma relação de laços fortes, enquanto outros podem experimentar um tipo de "comunidade momentânea" ao treinar com outras pessoas ou participando com outros corredores de competições. Desse modo, além dos laços fortes existentes dentro das comunidades iniciais (dos corredores sérios que se expressam e se comunicam somente sobre a corrida), agora há também a incidência de laços fracos, impulsionados por essa comunidade momentânea, que é possível quando integrantes dos corredores sérios se 
inserem em outros grupos, proporcionando troca de informações e experiências que farão parte dessa nova comunidade momentânea. No entanto, não se pode afirmar que exista uma união com temas relevantes ao bem comum da sociedade como a responsabilidade social corporativa.

Outro elemento considerado importante, citado por Bauman (2001) e reforçado por Pedersen et al., 2018, é o embate quase dicotômico entre "liberdade versus segurança" e "individualidade versus comunidade". Maior liberdade ou segurança ocorrerá às custas um do outro, o que faz com que este seja mais um fator que merece reflexão no mundo da modernidade líquida, pois no momento em que se proporciona mais segurança, o indivíduo pode perder um pouco de sua liberdade. O contrário também é verdadeiro: no momento em que se tem mais liberdade, perde-se um pouco da segurança. $\mathrm{O}$ mesmo processo gera a dualidade entre individualidade e a comunidade: quanto mais acentuado é o senso de comunidade, a individualidade fica enfraquecida e, por outro lado, quanto mais individualidade se tem, menor é o sentido de comunidade.

Por outro lado, na busca de entendimento da cocriação em uma comunidade, Fujita, et al. (2018) procuram identificar como o conteúdo cocriado pode facilitar experiências relevantes e significativas de clientes em comunidades de marcas sociais, porém apontam como gap de sua pesquisa, a ausência de verificação em redes sociais.

Nesse mesmo sentido, entendendo como ocorre a cocriação e seu impacto na comunidade, Cannas et al. (2018) exploram o conceito de cocriação de valor em um banco italiano, identificando que as pequenas e médias empresas pertencentes ao Sardex, uma moeda comunitária estritamente entrelaçada com a sua comunidade local, cocria valor por meio de valores sociais, tal como a reciprocidade incondicional. Assim, além de promover intercâmbios na cadeia de suprimentos, se envolvem com provedores locais, gerando círculos virtuosos de confiança que impactam positivamente a economia local. No entanto, colocam como gap de pesquisa, a ausência de uma análise aprofundada dos stakeholders, que seria necessária para explicar melhor o papel da comunidade local na criação de valor coletiva.

Dessa forma, suportado por esses estudos e no contexto do presente ensaio, estabelecemos o pressuposto de que há conexão entre a comunidade de Bauman e o sentido de comunidade existente nos diálogos virtuais nas comunidades de RSC. Desse modo, propomos um alinhamento entre as discussões sobre a modernidade líquida, responsabilidade social corporativa e cocriação de valor em comunidades virtuais de RSC.

Segundo Bauman (2003), a palavra comunidade traz uma sensação boa a todos; é diferente de falar que alguém anda em má companhia. Quando se está em uma comunidade ou quando se "anda" em comunidade, significa dizer que está no caminho certo; dentro da comunidade, não há o perigo "lá de fora" (Bauman, 2003). Dentro da perspectiva baumaniana em uma comunidade, todos se entendem; e é possível confiar uns nos outros. Desse modo, a comunidade é um local seguro e protegido; uma entidade internamente homogênea e harmoniosa, limpa de toda substância estranha. Todos têm como objetivo comum melhorar a vida uns dos outros. O sentido da comunidade nos dá a sensação de que tudo o que sentimos falta é o que precisamos para vivermos seguros e confiantes (na modernidade líquida). O preço que pagamos por viver em comunidade, é o preço da liberdade, da autonomia e da própria identidade.

O ambiente de diálogos virtuais de RSC é como a proposição que Bauman (2001) faz dizendo que a imagem da comunidade é de uma ilha de tranquilidade envolta em um mar de turbulência e hostilidade? Ele utiliza esta metáfora por entender que a tentativa de domar os mares já foi retirada da agenda ou é apenas uma proposta suspeita e irreal. Dessa forma, ele descreve a suposta segurança existente quando estamos em uma comunidade. Assim, a comunidade se torna sinônimo de segurança.

Ressalta-se que o objetivo deste ensaio teórico não é fornecer respostas conclusivas aos questionamentos, mas desenvolver um primeiro esforço de pesquisa no sentido de apontar e demonstrar a semelhança entre os elementos - a dimensão da comunidade de Bauman explorada e os diálogos virtuais de RSC. Acredita-se que tais evidências poderão conduzir à construção de um cenário mais claro capaz de conectar o conceito de comunidade na modernidade líquida e a 
cocriação de valor de responsabilidade social corporativa. Espera-se, portanto, que estas reflexões possibilitem um maior entendimento de como ocorre a cocriação de valor em comunidades virtuais de responsabilidade social corporativa na perspectiva da sociedade líquido-moderna de Bauman.

\section{BASE TEÓRICA}

Conhecer as bases teóricas que circundam o tema proposto ajuda a clarificar a proposta deste ensaio. Assim, nessa seção, serão expostos os principais fundamentos acerca da Modernidade Líquida e Cocriação de valor em responsabilidade social corporativa.

\subsection{Modernidade Líquida}

Identificamos Zygmunt Bauman como o mais profícuo autor sobre pós-modernidade e modernidade líquida, termo este cunhado pelo próprio autor. Aliado a isto, destacamos a naturalidade com que ele expõe e exemplifica temas sociológicos, por vezes, complexos. Deste modo, torna-se referência neste trabalho. Como afirma Tomlinson (2007), na liquidez, o imediatismo, produzido pelas novas tecnologias de mídia, é o princípio cultural que cada vez mais substitui os fundamentos industriais da chamada modernidade sólida, o que é apropriado quando está se estudando o tema em redes sociais e suas respectivas comunidades virtuais.

$\mathrm{Na}$ modernidade líquida, não há uma agenda política definida, assim como também não há um ideal de vida formulado ou um projeto de sociedade estabelecido, como havia na modernidade sólida. A vida na modernidade líquida é mais adaptada ao meio, apresenta fluidez, impossível aos sólidos que têm como princípio não alterar suas formas. Beilharz (2018) argumenta que o conceito de modernidade líquida é sobre contrastar o sólido mundo ocidental moderno do fordismo no pósguerra com o modo como vivemos agora, onde o princípio da descontinuidade governa.

Outras pesquisas ilustram, conforme apontado por Bardhi e Eckhardt (2017), que essa transformação ocorrida na sociedade impacta os rituais e as práticas de consumo que cercam as instituições. Como exemplo, tomam o casamento gay para mostrar que as práticas e rituais conservadores estão sendo revisados por uma lógica não-binária, ou como Bauman (2001) comenta: as estruturas familiares não são mais as mesmas. Isso está alinhado também a uma nova concepção da própria sociologia. Latour (2012), por exemplo, defende uma sociologia das associações e revisita toda lógica binária que constituiu as características de atores, incluindo supremacias de classe.

Há ainda o clamor por perspectivas críticas e culturais, como exposto por Herbert et al. (2018), que defendem essa análise sobre o ponto de vista econômico, enfatizando a adaptação dos varejistas às mudanças. Nisto, destaca-se que a vida líquida e a sociedade moderna líquida alimentam-se mutuamente e as estratégias que os atores implantam envelhecem rapidamente e não podem confiar em eventos passados. Na vida líquida tudo se adapta, tudo flui com mais naturalidade e com maior rapidez.

$\mathrm{Na}$ análise dessa fluidez, Bauman (2001) aborda as dimensões da emancipação, individualidade, tempo/espaço, trabalho e comunidade, com o intuito de descrever como ocorreu a passagem da modernidade sólida para a fase da modernidade líquida (Tabela 1). Ele escolheu essas dimensões, pois elas são dotadas de conceitos em torno dos quais as narrativas da condição humana tendem a se desenvolver. 


\section{Tabela 1 - Dimensões da modernidade líquida}

\begin{tabular}{l|l}
\hline \multicolumn{1}{c|}{ Dimensão } & \multicolumn{1}{c}{ Características } \\
Emancipação & $\begin{array}{l}\text { O homem não é livre; tem apenas uma autonomia relativa, pois há dependência de outros } \\
\text { indivíduos (embora queira tornar-se livre da sociedade). No entanto, essa liberdade traz } \\
\text { consequências, dentre elas, a responsabilidade por seus atos. }\end{array}$ \\
\hline Individualidade & $\begin{array}{l}\text { O indivíduo utiliza o modelo de influência de celebridades, perdendo a sua essência, sua } \\
\text { individualidade. Dessa forma, ele não é ele, e nem o modelo a ser seguido. Para ele, vale } \\
\text { tudo em busca da sua individualidade: o consumo em busca da diferenciação e das regras } \\
\text { que são ditadas. A sociedade é controlada, há uma exposição da vida nas redes sociais; o } \\
\text { homem está preso na sua própria tecnologia. }\end{array}$ \\
\hline Trabalho & $\begin{array}{l}\text { Preza pela facilidade de desempenhar diversas funções ao mesmo tempo, com agilidade e } \\
\text { sem perda de tempo, fazendo sobrar mais tempo para o consumo. }\end{array}$ \\
\hline Comunidade & $\begin{array}{l}\text { A relação entre patrão e empregado mudou. Agora há um maior poder de negociação entre } \\
\text { as partes, diferente do que ocorria na modernidade sólida. }\end{array}$ \\
$\begin{array}{l}\text { O convívio ainda existente, mas de laços individualizantes. Vida social individual acima } \\
\text { da vida coletiva. }\end{array}$
\end{tabular}

Fonte: Baseado em Bauman (2001)

Na emancipação, há a ideia de sentir-se livre das limitações que o mundo nos impõe. Estamos livre para agir conforme nossos desejos, nos levando a atingir o "[...] equilíbrio entre os desejos, a imaginação e a capacidade de agir" (Bauman, 2001, p. 26). Ele sustenta que a anomia (a ausência ou a falta de clareza das normas), apenas incapacita nossa vida no cotidiano, pois com ela, apenas sobra a dúvida e o medo. Esse conceito difere da rotina que, segundo Sennet (1998), pode nos reduzir como seres pensantes, mas também pode nos proteger. Diderot (1976), por sua vez, não acreditava que o trabalho rotineiro fosse algo degradante; pensava, ao contrário, que uma vida feita de impulsos momentâneos, sem rotinas sustentáveis, é uma existência sem sentido.

Para abordar o conceito de individualidade, Bauman traz como exemplo os atores e as celebridades que nos convencem a ser como eles. Isso é possível se desempenharmos tal papel ou se tivermos determinadas ações. Ele relata, por diversas vezes, que somos induzidos a procurar exemplos e não líderes. Desse modo, o que mais nos atrai é o que pessoas públicas, tais como políticos e celebridades, fazem em suas vidas privadas. Ao querermos perseguir seu estilo de vida, seu modus operandi, estamos perdendo nossa própria individualidade, pois não podemos ser eles e acabamos abdicando de ser nós mesmos.

Bauman também faz uma alusão ao capitalismo leve e pesado: o fordismo, com suas estruturas pesadas, sólidas e volumosas era o representante mais fiel da ideia de capitalismo pesado (e da sociedade moderna), no qual para ser importante e respeitado, era preciso manter uma estrutura rígida, com pessoas muito especializadas em suas funções, seguindo um roteiro prédeterminado; uma ordem. Já o capitalismo leve é caracterizado, ao contrário do pesado, como a realização de uma viagem apenas com uma bagagem de mão, um celular e um computador portátil; não há mais necessidade e nem se tolera mais o que é volumoso e pesado.

Para elucidar a dimensão tempo/espaço, Bauman discorre sobre os conceitos separadamente. Enquanto o tempo pode ser alterado e manipulado, o espaço é o que pode ser percorrido em determinado tempo (Bauman, 2001). O autor contextualiza os conceitos por meio de dois exemplos de categorias de espaços públicos distintos: um centro de negócios específico e os lugares de consumo em geral. O primeiro exemplo corresponde ao La Défense em Paris, que se constitui um imponente centro de negócios fora do eixo turístico da cidade, que, porém, é marcado pela falta de hospitalidade. Não se avistam turistas, tampouco mendigos, ou qualquer outro ser que não seja nos horários previstos do metrô. Também não há bancos para sentar ou árvores para se proteger. Essa categoria estaria mais relacionada ao espaço. A categoria tempo, aparece vinculada ao segundo exemplo que está voltado a transformar o cidadão em consumidor. Os lugares de consumo encorajam a ação e não a interação. Podem ser shopping centers, salas de espetáculo, cafés, dentre outros. Nesses lugares, a tarefa é o consumo e tão somente ele. 
Quanto ao trabalho, Bauman é enfático ao argumentar que a questão menos respondível em nosso mundo contemporâneo não é "o que fazer?" e sim, “quem irá fazer?" Ele também relata a importância a que o trabalho foi alçado no mundo moderno, sendo atribuídos virtudes e efeitos benéficos a ele, como o aumento da riqueza, a eliminação da miséria e sua contribuição para o estabelecimento da ordem: "[...]colocar a espécie humana no comando de seu próprio destino" (Bauman, 2001, p. 172). O trabalho foi definido como um esforço de toda a humanidade, em que cada membro deveria participar. Colocar o trabalho como condição natural, sendo que aqueles que estivessem sem trabalho, como possuidores de alguma "anormalidade"; assim como colocar no trabalho a primeira entre as atividades humanas e como elevação dos padrões éticos da sociedade, eram consequências naturais.

Ao mesmo tempo, as relações do trabalho também mudaram, tanto na relação patrãoempregado quanto na sua execução. Hoje há os freelancers, baseados em contratos e acordos de trabalho flexíveis, como expõe Pinsker (2015), e mesmo a transformação do escritório tradicional em um espaço de coworking, conforme exemplificam Toussaint et al. (2014), assim como a construção colaborativa de conteúdo digital, como é o caso do Wikipédia (Jemielniak \& Raburki, 2014). Para Bauman (2001), o trabalho não pode mais se prender no padrão pesado e volumoso da fase sólida da modernidade, o trabalho agora adquiriu uma significação estética no qual poucos têm o prestígio pela importância e benefício comum gerados pelo trabalho que realizam. A pessoa (trabalhador) é mais valorizada pela sua capacidade de alegrar e entreter, satisfazendo não tanto a vocação do produtor e criador, mas para satisfazer as necessidades e desejos estéticos do consumidor, que procura sensações e coleciona experiências.

Dentro da dimensão comunidade, ponto central deste ensaio, Bauman (2001) reflete que a comunidade ideal é um mundo que oferece tudo que se precisa para levar uma vida plena e que a compense e que ela sempre traz um sentimento bom. No entanto, vale destacar aqui a diferença entre sociedade e comunidade: a sociedade está relacionada aquilo que é arcaico, enquanto a noção de comunidade, traz à tona o conceito de moderno; ou de que é uma "boa sociedade" (Albuquerque, 1999). Assim, tem-se buscado na comunidade a solução para muitos problemas existentes na modernidade.

Ainda refletindo sobre a comunidade, Bauman (2001) diz que é importante para o indivíduo participar do meio e interagir com ele, mesmo que haja a dicotomia entre liberdade e as regras estabelecidas. As comunidades virtuais de responsabilidade social corporativa também propiciam essa interação? Elas são livres para os usuários que nela estão inseridos? Korschun e Du (2013) estabelecem que pessoas, mesmo aquelas sem as devidas credenciais, podem participar dos diálogos virtuais de RSC e cocriar, ponto que elencam quando tratam da participação no diálogo de RSC. Na visão de Bauman (2001), essa falta de credenciais também é possível em qualquer tipo de comunidade, mas será que isso é percebido mesmo em uma comunidade virtual? Se isso realmente for verdadeiro, todos podem falar o que desejam em uma comunidade virtual, sem que tenham propriedade sobre determinado assunto - e falam! - independentemente de sua formação técnica ou nível de propriedade sobre conhecimento do assunto.

Fletcher e Swain (2016) utilizam o conceito de comunidade para identificar o comportamento das equipes de críquete em uma região do Reino Unido. Sendo este historicamente um esporte associado a homens brancos privilegiados e, apesar de enfrentar manifestações antirracistas de grupos minoritários étnicos, seus praticantes ainda possuem orgulho em sua prática. $\mathrm{Na}$ busca em permanecer afastados dos espectros de medo e insegurança causados pelo ambiente externo, cada vez mais diverso e global, o esporte tem se mantido em espaços sociais fechados, na tentativa de manter uma aparência de comunidade. E mesmo dentro das ligas, as equipes são uniformizadas etnicamente para manter níveis de segregação pela imposição de barreiras baseadas em noções simbólicas de autenticidade que facilitam o sentimento de pertencimento à equipe e à comunidade. Os autores concluem que o crescente sentimento de insegurança e isolamento, faz com que os grupos (equipes de críquete) tentem superar esses fatores pertencendo a grupos ou comunidades estáveis. 
Com base nos estudos de Bauman (2001), Pedersen e Thing (2016) desenvolvem seu trabalho identificando o sentido de comunidade entre os corredores de rua sobre suas experiências de pertencimento. Os resultados de sua pesquisa mostram que as comunidades da modernidade líquida agem como pontes entre desejos contraditórios e entre a necessidade de individualidade e comunidade. Os corredores experimentam uma comunidade 'momentânea' ao treinar com outras pessoas ou se juntar a 'enxames' de corredores durante as competições, desafiando a dicotomia entre correr sozinho e correr organizado em clubes.

Por outro lado, Hurd e Dyer (2017) exploram o sentido de comunidade realizando sua pesquisa em uma pequena cidade da Nova Zelândia. Por meio de entrevistas, inicialmente os autores identificaram comentários relacionados à coesão na comunidade de trabalhadores. No entanto, com o progresso da quantidade de entrevistas realizadas, os comentários começaram a ir em uma direção contrária a normativa inicial, surgindo temas relacionados à demarcação de terras com base na etnia, ocupação e tempo gasto na cidade, problematizando a noção de uma identidade comunitária unificada. A pesquisa revela ainda que, apesar da noção que o senso de pertencimento não é mais relevante nesse mundo acelerado e móvel (líquido), para muitos essa busca por pertencimento e identificação permanece forte no nível do local (como foi demonstrado na cidade objeto do estudo).

Parece evidente a existência de um grande ponto de conexão entre o conceito de comunidade de Bauman e o conceito de comunidade na geração de valor, segundo Korschun e Du (2013). Para Bauman (2001, p. 222), na modernidade líquida, "[...]há agentes engajados na busca da autoidentificação; uma unidade que é um resultado, e não uma condição dada a priori, da vida compartilhada". Já para Korschun e Du (2013), os diálogos, antes de criarem resultados tangíveis, eles passam por um processo cognitivo de identificação com a comunidade de participantes, ou seja, essa suposta identificação dos usuários com a comunidade pode gerar valor para os diálogos que são criados nessas comunidades virtuais.

Assim como Latour (2012), que declara forte interesse pela transitoriedade, chegando a afirmar que não existe nem o social ao postular que há apenas mudanças de conexões entre recursos não sociais, Bauman (2001) cita a fragilidade e a transitoriedade dos laços como um preço do direito de os indivíduos perseguirem seus objetivos individuais e discute a ideia de segurança quando fala em comunidade. Para ele, a imagem de comunidade é de "[...]uma ilha de tranquilidade caseira e agradável num mar de turbulência e hostilidade" (p. 227). Essa sensação de segurança traz um valor adicional a nossos dias, nos quais outros valores são cada vez mais imprevisíveis de serem conquistados, cabendo aqui uma reflexão: sendo a comunidade um lugar seguro, como aponta Bauman, o mesmo o é nas comunidades virtuais? Elas também trazem segurança aos seus usuários? A discussão sobre responsabilidade social corporativa nestas comunidades oferece algum risco de sofrermos a ação do ambiente, dos usuários ou das empresas? Em outras palavras, as empresas ou usuários "credenciados", podem provocar alterações em nossa visão sobre determinado tema que esteja sendo discutido referente a responsabilidade social corporativa? Ou, talvez, poderíamos questionar: o pensamento de Bauman é perfeitamente aplicável a qualquer tipo de comunidade?

Também faz parte dessa discussão, assuntos polêmicos e presentes nas discussões em comunidades sociovirtuais. Alguns temas, tais como aborto, racismo, religião, dentre outros, podem ser alvo de motivação de ódio ou mesmo bullying. Se, por um lado, estas comunidades são hostilizadas por movimentos de integração da sociedade, por outro, unem atores com sentimentos comuns e promovem discussões que os aproxima. A deepweb, que fica oculta ao grande público, reúne muitos participantes com interesses em comum em debates polêmicos e até criminosos. Comunidades nesse sentido se configuram como canais de externalidades negativas com potencial de impactar a RSC, tal qual o posicionamento que as empresas assumam diante das discussões. 


\subsection{Cocriação de valor em responsabilidade social corporativa}

A ideia de cocriar valor está ligada à cooperação de múltiplos atores com interesse no resultado de determinada interação. $\mathrm{O}$ termo foi descrito primeiramente por Prahalad e Ramaswamy no ano 2000. Posteriormente, os debates cresceram no sentido de compreender de que forma os stakeholders poderiam ser engajados para construir valor de determinada troca. A cocriação, por si só, desse modo, se refere ao processo de interação entre empresa e consumidor, buscando criar bens ou serviços que tenham valor para ambas as partes (Grönroos, 2000; Prahalad \& Ramaswamy, 2000; Terblanche, 2014; \& Van Dijk et al., 2014). No entanto, quando lidamos com cocriação de valor em responsabilidade social corporativa, o campo se torna restrito e, ao mesmo tempo, instigante, dada a importância da discussão do tema de RSC no mundo virtual.

As principais definições para responsabilidade social corporativa dizem respeito às práticas e posturas adotadas em prol da sociedade e do ambiente natural. A importância crescente de fazer negócios de forma sustentável, de maneira que se garanta o futuro da organização e do meio no qual está inserida, terá impacto na forma como os programas de responsabilidade social corporativa são criados, implementados e comunicados (Dawkins \& Fraas, 2013). É importante, portanto, identificar como ocorre o processo de comunicação das ações de Responsabilidade Social Corporativa nas organizações em relação ao seu público-alvo (Frostenson et al., 2011; Waddock \& Googins, 2011; Dawkins \& Fraas, 2013).

Um dos principais objetivos das atividades da RSC é o aprimoramento das relações com todos os stakeholders, incluindo os consumidores e, neste ponto, a RSC se coloca próxima ao sentido de cocriação de valor. Um comportamento socialmente responsável leva à construção de valor por meio de estratégias legítimas do que se espera no âmbito institucional. Surge então o conceito de valor compartilhado que estaria, assim, relacionado à essência das perspectivas institucionais e dos stakeholders de um valor além de econômico, sustentável (Barrena Mrtínez et al., 2016).

Prahalad e Ramaswamy (2000) defendem que, para que haja cocriação de valor, é fundamental a comunicação dialógica na qual todos têm acesso à informação para ter escolhas de consumo conscientes e assertivas. Há também a compreensão de que a cocriação atuaria como meio para RSC, à medida que todos os públicos interessados têm possibilidade de decidir, todos podem ser beneficiados. Ramaswamy e Gouillart (2010) falam em "ecossistemas sociais" capazes de tornar a experiência humana mais significativa para todos, ao mesmo tempo em que tornam mais sustentáveis as competências empresariais. Neste sentido, podemos considerar a informação dialógica do ponto de vista da comunicação virtual.

Gruber et al. (2017) enfatizam que as empresas devem atender a dois tipos de consumidores: aqueles que já possuem interesse no tema e aqueles que não possuem uma forte atitude preexistente em relação a ele. Para o primeiro grupo, os autores aconselham as empresas a usar canais mais sutis, tais como homepages e relatórios de sustentabilidade online, pois, por meio deles, esse público busca informações mais detalhadas. Para o segundo grupo, os autores defendem a utilização de comunicação em larga escala, tais como televisão, mídias sociais e publicidade em rádio, pois esse público requer informações sobre as iniciativas sustentáveis da empresa. No entanto, para que as empresas aprimorem os relacionamentos com as partes interessadas, os indivíduos devem estar conscientes das atividades desenvolvidas por elas, ou seja, deve haver um alinhamento entre a empresa e o consumidor para que o objetivo seja atendido.

Como já postulado por alguns autores (Morsing \& Schultz, 2006; Du et al., 2010; Scharf \& Fernandes, 2013; Su et al., 2017), com uma comunicação adequada de responsabilidade social corporativa, as organizações podem, ao longo do tempo, construir uma imagem corporativa forte, bem como elevar o nível de engajamento com os stakeholders atuais, tornando esses, defensores da marca. Na pesquisa de Morsing e Schultz (2006) destaca-se que a passagem pelas corretas estratégias de comunicação de RSC, torna-se cada vez mais necessária não apenas para se adequar às expectativas dos stakeholders, mas também para influenciar essas expectativas. $\mathrm{O}$ trabalho 
evidencia a importância de envolver também stakeholders externos nos processos contínuos de "dar sentido" e "fazer sentido" na comunicação CSR.

Por sua vez, Scharf e Fernandes (2013) apresentam evidências de iniciativas de comunicação de RSC no setor bancário, que estimulam a consciência de marca, sem a utilização de aspectos comerciais. O trabalho de $\mathrm{Su}$ et al. (2017) caminha no mesmo sentido, os autores confirmaram, por meio de um estudo da indústria hoteleira de luxo chinesa, que a RSC afeta positivamente a reputação corporativa percebida e a satisfação do cliente, o que, por sua vez, afeta significativamente o compromisso do cliente e as respostas comportamentais (intenções de compra, fidelidade e indicação boca a boca). Como resultado desse movimento, as empresas passaram a dedicar recursos consideráveis à comunicação de Responsabilidade Social Corporativa.

O artigo de Korschun e Du (2013) apresenta um framework (Figura 1) que explica como os stakeholders interpretam e respondem aos diálogos virtuais de responsabilidade social corporativa. Nesse modelo, os autores evidenciam que os diálogos geram valor com base na identificação das partes interessadas com a comunidade de participantes do diálogo e com base nas expectativas aumentadas que os stakeholders desenvolvem.

Korschun e Du (2013) partem do pressuposto que as mídias sociais encorajam a comunicação entre os pares, o que pode criar um senso de comunidade em torno dos valores compartilhados pelos participantes. Bauman (2001) conceitua este sentido nas dimensões comunidade e emancipação; comunidade pela obviedade da palavra; e emancipação, por entender que isso pode alterar o senso da própria comunidade, ou seja, é um valor adaptado e não nascido com o indivíduo. Korschun e Du (2013) complementam, afirmando que os usuários das mídias sociais não são um público passivo, e sim cocriadores ativos de valor (Korschun \& Du, 2013). Essa cocriação pode ter efeitos profundos sobre as expectativas dos stakeholders ao informar à empresa e aos membros da comunidade sobre suas preferências.

Assim, Bauman entende que esse valor adaptado pode alterar o senso da própria comunidade, ou seja, é um valor adaptado e não nascido com o indivíduo. Na pesquisa de Korschun e Du (2013), os autores afirmam que os usuários das mídias sociais não são um público passivo, e sim cocriadores ativos de valor e quando as empresas os envolvem nos diálogos, eles estão prontos a contribuir ativamente por meio de trocas de informações ricas e, às vezes, pessoais (Korschun \& $\mathrm{Du}, 2013)$. Essa cocriação pode ter efeitos profundos sobre as expectativas dos stakeholders ao informar à empresa e aos membros da comunidade sobre suas preferências. 


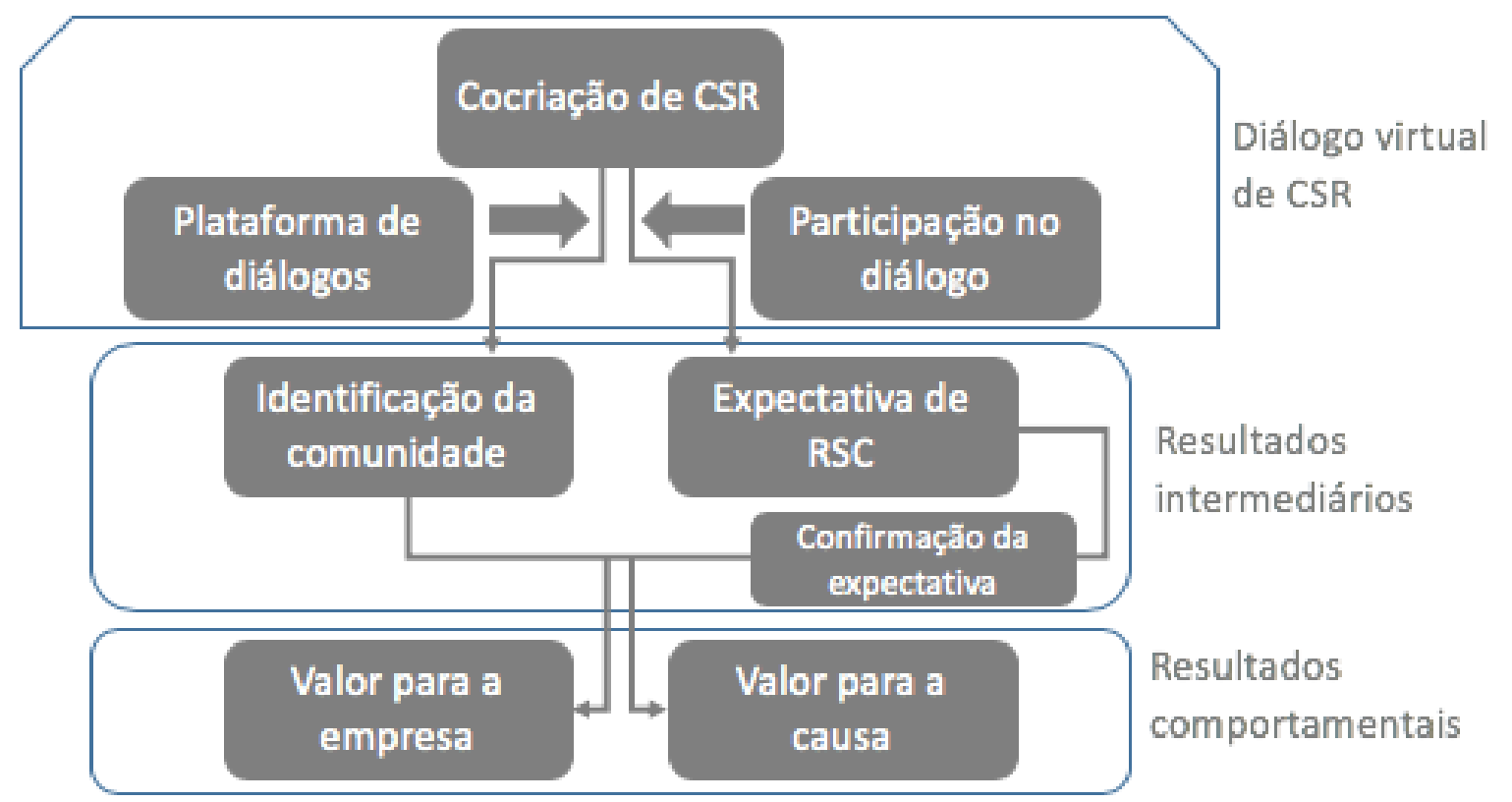

Figura 1 - Como os diálogos de RSC criam valor

Fonte: Adaptado de Korschun e Du (2013)

O modelo da figura 1, é composto por três blocos: as características do diálogo virtual de $\mathrm{RSC}$, os resultados intermediários dos diálogos virtuais de RSC e os resultados comportamentais dos diálogos virtuais de RSC. Especificamente nos resultados intermediários, Korschun e Du (2013) pressupõem que antes de os diálogos virtuais de RSC resultarem em comportamentos tangíveis, eles resultam em dois resultados cognitivos intermediários: levam à identificação com a comunidade de participantes no diálogo de CSR virtual, o que pressupõe conexão com o conceito de comunidade imputado por Bauman $(2001,2003)$. Tais resultados conduzem a reflexão sobre a importância dos diálogos existentes dentro das comunidades virtuais de RSC e a interação dos usuários nesse meio.

A dinâmica proporcionada pelas redes sociovirtuais, favorecem a conversão da competição em cooperação. Isso foi observado por Franco (2008) ao afirmar que as redes sociais favorecem a interação à medida que permitem a "[...]polinização mútua de muitos padrões de comportamento" (Franco, 2008, p. 112). Neste ponto, a identidade social e o contato intergrupal identificam-se com a comunidade, à medida que há interação frequente e também cooperação dos grupos em prol de um objetivo comum.

Com efeito, resgatamos a ideia de Granovetter (1973) sobre a possibilidade de uma identidade comum que se refere não mais ao indivíduo isolado, mas ao grupo o qual ele faz parte. Nestes termos, destaca-se a ideia de laços fortes que se originam nas redes sociais à medida que o grupo busca referências para tomada de decisão. A este respeito, Cavalcanti (2017) desenvolve um quadro (Figura 2) útil para compreensão da diferença na força dos laços como nas relações em comunidades virtuais. Dessa forma, a combinação dos fatores que geram laços fortes "[...]influenciam as decisões de modo que quanto mais fortes forem os laços, mais consistência há nas escolhas" (Cavalcanti, 2017, p. 38). Contudo, não podemos omitir que a presença de um objetivo comum nos laços fracos, também funciona como oportunidade aos indivíduos de integrarem-se em comunidades (Granovetter, 1983). Desse modo, os laços fortes geralmente integrariam um mesmo grupo, fortalecendo a ideia de comunalidade; enquanto os laços fracos potencializam a criação das redes sociais pela interação em diferentes grupos, aumentando o grau de inovação nestas relações (Granovetter, 1983; Kaufman, 2012).

Neste sentido, é possível entender a possibilidade de cocriação de valor nas comunidades sociovirtuais também por aqueles que desenvolvem laços fracos, ou pouco fortes nas comunidades. 


\section{Laços fracos}

Conhecidos, contatos casuais;

Tendem a ser diferentes uns dos outros;

Presentes em diferentes círculos sociais

\section{Recursos e trocas de informaç̃es}

Pouca frequência; com fim instrumental; Compartilham informação ou fornecem apoio

Baixa motivação para compartilhar recursos

\section{Força dos laços fracos}

Experiência, informação, atitude, recursos e contatos de diferentes esferas sociais, o que proporciona maior grau de inovações

\section{Laços fortes}

Amigos, colegas de trabalho, familiares;

Apresentam semelhanças;

Integram mesmo círculo social

\section{Recursos e trocas de informações}

Frequentes; a finalidade pode compreender $\mathrm{o}$ instrumental e emocional

Reciprocidade nas trocas de recursos.

\section{Força dos laços fortes}

Alta motivação para compartilhar os recursos que possuem pela elevada confiança;

Incentivam a tomada de decisão dos envolvidos.

Figura 2: Diferenças da força dos laços

Fonte: Cavalcanti, 2017, p. 39

No contexto de formação de laços pelo compartilhamento de informações e criação de grupos, temos a ideia de Bauman (2003) de que a comunidade é um lugar seguro, onde todos se sentem bem e sempre recebem ajuda uns dos outros e que remete a um sentimento positivo quando se faz referência a ela. Entende-se, portanto, que mesmo numa comunidade de RSC, o sentimento de comunidade pode estar presente, ainda que em um grau diferente, porém, com o intuito de preservar os seus membros e a identidade do grupo, de forma mais ampla. Desse modo, pontua-se a existência de uma conexão entre o fragmento do modelo de Korschun e Du (2013) da cocriação de valor, apresentado na Figura 1 e a comunidade de Bauman (2001). Isso permite retomar o questionamento de forma inversa: a partir de um modelo teórico de cocriação de valor por meio de diálogos virtuais de responsabilidade social corporativa podemos encontrar a comunidade de Bauman? Mais claramente: com os diálogos que ocorrem nessas comunidades virtuais, é possível chegar aos mesmos conceitos colocados por Bauman? Será que os laços criados dentro desses tipos de comunidades ocorrem de forma homogênea, criando uma identidade comum nos clusters, como Granovetter (1973) denomina de laços fortes e, dessa forma, se estabelecem da maneira como Bauman acredita?

Essas reflexões são necessárias para entender se a identificação da comunidade é capaz de gerar valor para a empresa, conforme postulam Korschun e Du (2013) mesmo em uma comunidade não virtual. Ou seja, entender se a partir do momento em que o indivíduo se insere na comunidade, ele está apto a cooperar adotando para si a identidade do grupo, compartilhando valores e crenças em comunicação dialógica com outros membros. É sabido que a interação entre os membros, por meio de diálogos em uma comunidade virtual, é intensa, mas não se sabe se o sentido de comunidade indicado por Bauman também propicia esse valor para as organizações.

Desse modo, a identificação da comunidade na perspectiva de Korschun e Du (2013) está apoiada tanto nos pesquisadores de mídias sociais quanto nos pesquisadores de RSC que, por sua vez, se baseiam na literatura sobre identidade social e contato entre grupos, indicando que quando indivíduos ou grupos interagem e cooperam para alcançar um objetivo comum, eles podem reconfigurar a identidade do grupo, criando um grupo comum que abrange todos os participantes. Assim, se questiona, se o sentido de comunidade de Bauman, corrobora para que isso seja alcançado, trazendo a segurança de estar dentro de uma comunidade como um importante elemento para atingir essa identidade de grupo.

Já no produto resultante, os resultados comportamentais propiciam que os diálogos são capazes de aumentar as expectativas e a identificação com a comunidade. No modelo proposto por Korschun e Du (2013), os autores revelam duas formas de valor que são criadas por diálogos de CSR virtual: valor para a empresa e para a causa. No valor para a empresa, Korschun e Du (2013) 
estabelecem que, ao estimular os stakeholders a expressar plenamente seus valores por meio de diálogos virtuais de RSC, a empresa pode tornar a participação dos stakeholders em um relacionamento "sinérgico" entre as partes interessadas e a empresa - isso ocorre em qualquer comunidade ou apenas em comunidades de RSC? No valor para a causa, à medida que as expectativas de CSR de um stakeholder aumentam, os participantes dos diálogos virtuais de CSR se comportarão de maneira a gerar valor para a causa.

\section{CONSIDERAÇÕES FINAIS}

Este ensaio teórico reconhece a complexidade do tema da modernidade líquida e tenta situar o leitor sobre o mesmo, também expandindo seus conhecimentos sobre a comunicação de responsabilidade social corporativa e sobre uma provável conexão existente entre os temas cocriação de valor na comunicação de responsabilidade social corporativa e modernidade líquida.

Assim, a tentativa de identificação de possíveis conexões entre os dois sentidos de comunidade - o de Bauman, no sentido de entender o aspecto macrossocial e o da cocriação de valor nos diálogos de responsabilidade social corporativa, em conjunto com as lacunas na literatura expostas anteriormente, tornam o debate relevante, dado a emergência tanto da busca da responsabilidade pelas organizações quanto pela utilização das redes sociais para esse fim em nossos dias.

Procurou-se com este ensaio abordar a modernidade líquida de Bauman, bem como um ponto específico da comunicação de responsabilidade social corporativa - a cocriação de valor que é buscada por meio dos diálogos virtuais nas comunidades virtuais, procurando não apenas respostas, mas apresentando questionamentos baseados nas teorias existentes que possam conduzir a reflexões mais consistentes sobre o tema e que possam expandir o estudo sobre o tema na academia.

Supomos que a sensação de segurança proporcionada pela comunidade adiciona um novo valor aos nossos dias, contudo, poderia este valor, se adicionado no contexto das comunidades virtuais? Desse modo, pesquisas futuras poderiam verificar a sensação de segurança dentre membros de comunidades virtuais e conhecer os antecedentes que levam à sensação de segurança ou que alteram esta sensação. De outro modo, outras pesquisas podem investigar a aplicação do próprio conceito de comunidade e se este pode ser extensivo às comunidades virtuais. Uma possibilidade é contrapor o conceito de rede que supõe um distanciamento maior entre os membros.

Neste ensaio, suportamos teoricamente que é possível a conexão entre a comunidade de Bauman e o sentido de comunidade existente nos diálogos virtuais nas comunidades de RSC ou seja, esses dois elementos agem como se houvesse a presença de laços entre eles. Esse respaldo se dá pela visão de Bauman a respeito do sentido de comunidade impulsionado pela comunicação. Também os estudos de Granovetter $(1973 ; 1983)$, embora não façam referência à comunicação em redes sociovirtuais, sinalizam que os laços em redes sociais são elementos capazes de contribuir para a coesão social.

Encorajamos o desenvolvimento de pesquisas empíricas no sentido de responder às questões levantadas neste ensaio, tomando essa discussão como ponto de partida. Estudos de abordagem qualitativa, podem adicionar o pensamento de outros sociólogos que abordem o aspecto macrossocial ou até político, ou ainda, explorar alguns dos que aqui foram citados. Abordagens quantitativas, tal como análise de redes sociais, por exemplo, podem avaliar as hashtags disseminadas por stakeholders ligados às organizações nos diálogos de RSC.

É possível falar na construção de uma identidade comum a partir da conexão evidente entre a comunidade na qual estão ocorrendo diálogos de RSC entre os indivíduos. O ensaio enfatiza como o próprio senso de comunidade, expresso na dimensão estabelecida por Bauman, por meio de um correto alinhamento e entendimento sobre esses dois conceitos pode conduzir a uma forma mais assertiva de realizar a comunicação, de forma que ela esteja adequada aos tempos líquidos no qual vivemos.

Revista de Gestão Social e Ambiental - RGSA, São Paulo, v. 14, n. 2, p. 20-36, maio/ago. 2020. 
Pesquisas na perspectiva macrossocial apontam para a importância dos meios de comunicação como pressuposto nos diálogos virtuais nas comunidades de responsabilidade social corporativa (Weber \& Francisco-Maffezzolli, 2016; Chaves e Dantas, 2020; Lemos, 2020). No entanto, isso pode não se mostrar efetivo na sociedade líquido-moderna, pois, conforme estabelecido por Chávez (2018), a informação líquida - aquela que ocorre nas redes sociais sem a existência de verificação ou confirmação da informação que está em discussão, pode contrapor aos objetivos dos diálogos que surgem na comunicação de RSC, pois buscam a geração de valor com base nas expectativas geradas pelos diálogos virtuais de RSC. Nisto, há a necessidade de a informação seja correta em relação às ações desempenhadas pelas organizações e o apoio ou não dos indivíduos que participam desses diálogos. Conforme Chávez (2018) explica, essa liquidez da informação pode contrariar os princípios de uma comunicação de RSC adequada e, portanto, não contribuir para a geração de valor nessas comunidades.

Com este estudo inicial e com as indicações apontadas como futuros trabalhos, as organizações podem se beneficiar no esforço de desenvolver uma comunicação mais efetiva e direcionada aos novos tempos, com fluidez tanto nas comunicações quanto nos relacionamentos (entre indivíduos, entre empresas ou entre indivíduos e empresas). Ao mesmo tempo, esse estudo propõe fazer uma contribuição teórica à academia no sentido de trazer novas perspectivas que unam, de maneira efetiva, a sociologia e a comunicação de responsabilidade social corporativa, com vistas à ampliação da teoria e aplicação sobre discussões voltadas à cocriação de valor nas comunidades virtuais de RSC. Desse modo, é possível pensar um novo modelo de cocriação de valor de responsabilidade social corporativa no âmbito da modernidade líquida.

\section{REFERÊNCIAS}

Albuquerque, L. (1999). Comunidade e sociedade : conceito e utopia. Raizes, 20(1), 50-53.

Bardhi, F., \& Eckhardt, G. M. (2017). Liquid consumption. Journal of Consumer Research, 44(3), 582-597.

Bauman, Z. (2001). Modernidade líquida. Rio de Janeiro: Zahar.

Bauman, Z. (2003). Comunidade (Zahar, ed.).

Bauman, Z. (2008). Vida para consumo - Zygmunt Bauman.

Beilharz, P. (2018). The legacy of Zygmunt Bauman. Journal of Sociology, 54(3), 294-299.

Bortree, D. S. (2014). The state of CSR communication research : a summary and future direction. Public Relations Journal, 8(3), 1-8.

Cannas, R., Argiolas, G., \& Cabiddu, F. (2018). Fostering corporate sustainability in tourism management through social values within collective value co-creation processes. Journal of Sustainable Tourism, 0(0), 17.

Casas, F. (2005). Desafios autais da Psicologia na Intervenção Social. Psicologia \& Sociedade, $17(2), 42-49$.

Cavalcanti, H. (2017). Deu Match! As trocas nos relacionamentos virtuais e a objetificação do sujeito no Tinder. 
Chaves, V. M., \& Dantas, A. G. A. (2020). Espetáculo à mesa: midiatização da cozinha nos reality shows de gastronomia. Revista Mídia e Cotidiano, 14(2), 244-260.

Chávez, A. R. (2018). Liquid information in the post-truth era. Revista General de Información y Documentación, 28(1), 283-298.

Cruz, B. D. P. A. (2013). Boicote de consumidores em relação à responsabilidade social corporativa: proposições a partir do contexto brasileiro. Revista de Gestao Social e Ambiental.

Dawkins, C. E.;Fraas, J. W. (2013). An exploratory analysis of corporate social responsibility and disclosure. Business \& Society, 52(2), 245-281.

Diderot, D. (1976). Euvres esthétiques. Garnier, Paris.

Ethos. (2002). Responsabilidade social das empresas - Percepção do consumidor brasileiro. Retrieved from http://www.ethos.org.br/_Uniethos/Documents/consumidor_200 2.pdf.

Fletcher, T., \& Swain, S. (2016). Strangers of the north: South Asians, cricket and the culture of 'Yorkshireness'. Journal for Cultural Research, 20(1), 86-100.

Frostenson, M., Helin, S., \& Sandström, J. (2011). Organising corporate responsibility communication through filtration: a study of web communication patterns in swedish retail. Journal of Business Ethics.

Fujita, M.; Harrigan, P.; Soutar, G. N. (2018). The strategic co-creation of content and student experiences in social media: an identity theories perspective. Qualitative Market Research: An International Journal The, 2-32.

Granovetter, M. (1983). The strength of weak ties: a network theory revisited. Sociological Theory, l(1983), 201.

Granovetter, M. S. (1973). The strength of weak ties. American Journal of Sociology, 78(6), 13601380.

Gray, R., Kouhy, R., \& Lavers, S. (1995). Corporate social and environmental reporting a review of the literature and a longitudinal study of UK disclosure. Accounting, Auditing \& Accountability Journal, 8(2), 47-77.

Grönroos, C. (2000). Creating a relationship dialogue: communication, interaction and value. The Marketing Review, 1(1), 5-14.

Gruber, V., Kaliauer, M., \& Schlegelmilch, B. B. (2017). Improving the effectiveness and credibility of corporate social responsibility messaging: an Austrian model identifies influential CSR content and communication channels. Journal of Advertising Research, 397-409.

Herbert, M., Robert, I., \& Saucède, F. (2018). Going liquid: French food retail industry experiencing an interregnum. Consumption Markets and Culture, 21(5), 445-474.

Hildebrand, D., Sen, S., \& Bhattacharya, C. B. B. (2011). Corporate social responsibility: A corporate marketing perspective. European Journal of Marketing, 45(9/10), 1353-1364. 
Comunidade da modernidade líquida e cocriação de valor na responsabilidade social corporativa

Hurd, F., \& Dyer, S. (2017). "We're all in this together"? The search for collective belonging in a globalised single industry town. International Journal of Sociology and Social Policy. Vol. 37 Issue: $1 / 2$, pp.106-122.

Jemielniak e Raburki. (2014). Liquid Collaboration in Liquid Organization: Zygmunt Bauman and Organization Theory (Routledge, Ed.). London.

Kaufman, D. (2012). A força dos "laços fracos" de Mark Granovetter no ambiente do ciberespaço. Galaxia, 1(23), 207-218.

Kim, S. (2017). The Process Model of Corporate Social Responsibility (CSR) Communication: CSR Communication and its Relationship with Consumers' CSR Knowledge, Trust, and Corporate Reputation Perception. Journal of Business Ethics, 154(4), 1143-1159.

Korschun, D., \& Du, S. (2013). How virtual corporate social responsibility dialogs generate value: A framework and propositions. Journal of Business Research, 66(9), 1494-1504.

Latour, B. (2012). Reagregando o social: uma introdução à Teoria do Ator-Rede. Salvador: Edufba.

Lazzarato, M. (2006). As revoluções do capitalismo. Civilização Brasileira.

Morsing, M., \& Schultz, M. (2006). Corporate social responsibility communication: stakeholder information, response and involvement strategies. Business Ethics: A European Review, 15(4), 323338.

Lemos, A. (2020). Epistemologia da comunicação, neomaterialismo e cultura digital. Galáxia (São Paulo), (43), 54-66.

Pedersen, H., Pedersen, L., \& Thing, L. (2018). Liquid running communities - an analysis of serious runners' communities. European Journal for Sport and Society, 0(0), 1-16.

Pedersen, H., \& Thing, L. (2016). "Running for life": a theoretical sociological analysis of running culture. Idrottforum.Org, 1-16.

Pinsker, J. (2015). What Does the On-Demand Workforce Look Like? Retrieved from http://www.theatlantic.com/business/archive/2015/05/ what-does-the-on-demand-workforce-looklike/393680/.

Polivanov, B. (2013). Etnografia virtual, netnografia ou apenas etnografia? Implicações dos conceitos. Esferas, 1(3), 61-71. Recebido em: 10 fev.2020, de:

https://portalrevistas.ucb.br/index.php/esf/article/view/4621/3243.

Prahalad, C. K., \& Ramaswamy, V. (2000). Co-Opting Customer Competence. Harvard Business Review, 78(1), 79-90.

Sales, M. M., de Freitas Fonseca, J. C., \& Silva, B. C. (2019). Uma perspectiva crítica da responsabilidade social empresarial: histórico, práticas correntes e controvérsias. Pretextos-Revista da Graduação em Psicologia da PUC Minas, 4(8), 354-372.

Saraiva, K., \& Veiga-Neto, A. (2009). Modernidade líquida, capitalismo cognitivo e educação contemporânea. Educação \& Realidade, 34(2). 
Scharf e Fernandes, J. (2013). The advertising of corporate social responsibility in a Brazilian bank. International Journal of Bank Marketing, 31(1), 24-37.

Sen, S., Gürhan-Canli, Z., \& Morwitz, V. (2001). Withholding consumption: a social dilemma perspective on consumer boycotts. Journal of Consumer Research, 28(3), 399-417.

Sennet, R. (1998). The corrosion of character: the personal consequences of work in the new capitalism. New York.

Su, L., Pan, Y., \& Chen, X. (2017). Corporate social responsibility: Findings from the Chinese hospitality industry. Journal of Retailing and Consumer Services.

Terblanche, N. S. (2014). Some theoretical perspectives of co-creation and co-production of value by customers. Acta Commercii, 14(2), 1-8.

Tomlinson, J. (2007). The culture of speed: the coming of immediacy (Sage.Toussaint, Ed.). London.

Toussaint; Ozcaglar-Toulouse; Eckhardt. (2014). Accessing and Producing Liquid Places. Retrieved from http://www.theatlantic.com/business/archive/2015/05/ what-does-the-on-demandworkforce-look-like/393680/

Uzunoğlu, E., Türkel, S., \& Yaman Akyar, B. (2017). Engaging consumers through corporate social responsibility messages on social media: an experimental study. Public Relations Review.

Van Dijk, J., Antonides, G., \& Schillewaert, N. (2014). Effects of co-creation claim on consumer brand perceptions and behavioural intentions. International Journal of Consumer Studies, 38(1), $110-118$.

Waddock, S.; Googins, B. K. (2011). The paradoxes of communicating corporate social responsibility. The Handbook of Communication and Corporate Social Responsibility (Chapter 2. Oxford: Wiley-Blackwell, Ed.).

Weber, T. B. B., \& Francisco-Maffezzolli, E. C. (2016). Mídia, Consumo e a Adultização de Crianças: Uma Reflexão Macrossocial. In Atas do Congresso de Ciências da Comunicação na Região Sul, 17,Curitiba, PR (26).

Yin, J., Feng, J., \& Wang, Y. (2015). Social media and multinational corporations' corporate social responsibility in China: The case of conocophillips oil spill incident. IEEE Transactions on Professional Communication, 58(2), 135-153.

Este trabalho foi realizado com apoio da Coordenação de Aperfeiçoamento de Pessoal de Nível Superior - Brasil (Capes), por meio do Programa de Suporte à Pós-graduação de Instituições de Ensino Comunitárias (Prosuc), de acordo com a Portaria Capes nº. 149/2017. 